\title{
Research on Teaching Method of Mold Course Based on CAD/CAE/CAM Technology
}

\author{
https://doi.org/10.3991/ijet.v12i07.7224 \\ Xueyi $\mathrm{Li}^{*}$ \\ Shandong University of Science and Technology, Qingdao, China \\ lixueyio7etsinghua.org.cn \\ Shuhui Ding \\ Shandong University of Science and Technology, Qingdao, China \\ Junying Wei \\ Shandong University of Science and Technology, Qingdao, China \\ Quanwei Wang \\ Shandong University of Science and Technology, Qingdao, China
}

\begin{abstract}
The teaching of the traditional mold courses focus on the illustration of theoretical knowledge. Therefore, associating the design, evaluation, and manufacture links as a whole is difficult. Students cannot shape system knowledge, thereby making the study difficult. In addition, traditional teaching cannot meet the current enterprise needs of talents who have mold $\mathrm{CAD} / \mathrm{CAE} / \mathrm{CAM}$ technology. This study presents a teaching method that applies $\mathrm{CAD} / \mathrm{CAE} / \mathrm{CAM}$ technology to mold teaching. First, the positive effects of these technologies on the mold design and manufacturing process are introduced. Thereafter, lamp cover is used as an example to establish a series of computer-aided teaching development processes using existing software for mold design, mold flow analysis, and machining simulation. Lastly, survey results demonstrate that the effects of the proposed teaching method are better than the traditional method. Moreover, students and enterprises are substantially recognized in this teaching method.
\end{abstract}

Keywords-CAD/CAE/CAM, Mold design, Simulation, Teaching

\section{Introduction}

China has become a manufacturing power due to the development of its economy and technology. Mold is a special although basic process equipment in the manufacturing industry. This equipment is mainly used to produce the related components of industrial products with high efficiency and in large quantities. Moreover, the production process of mold generally utilizes precision manufacturing, computer technology, and intelligent control. The components produced by mold have the advantages of high consistency, precision, complexity, and low energy consumption. These compo- 
nents are extensively used in the machinery, aerospace, automotive, medical, and other manufacturing areas [1].

A typical university has introduced material shaping and control specialty to significantly convey the relevant scientific and technological personnel to social enterprises. In the traditional teaching method, knowledge of mold theory is illustrated in the classroom by teachers; thereafter, and the students perform experiments and develop course designs. The design, manufacture, and detection links of mold product design are mutually independent in this process. Accordingly, the students cannot form an entire knowledge system. Thus, students experience difficulty in understanding the complex mold structure and the specific action for open and closed moldings, thereby resulting in an unideal teaching efficiency.

In a fierce market competition environment, the traditional teaching method cannot adapt to the highly efficient, fast-paced actual production in modern enterprises. The development of computer technology has resulted in the increasing number of enterprises and universities to apply CAD/CAE/CAM technology to the teaching of mold. To provide students with an improved understanding and learning of the mold design, as well as to meet the needs of employees in different levels and types after graduation, this study proposes the application of computer-aided technology to the teaching of mold as an independent project for a case study.

\section{State of Art}

Traditional methods of teaching mold focus on the illustration of theoretical knowledge in the classroom [2]. However, the complex structure of mold prevents teachers from providing a clear verbal description, thereby resulting in the lack of practical abilities of students. To provide an improved understanding of mold class courses, Tempelman [3] proposed a teaching method for the study of injection molding and mold structure design in a university to reduce the theoretical time and exchange learning with professionals after the theoretical course, thereby enhancing the practical abilities of students. However, emphasizing the practice and neglecting mold design theory support cannot provide students with a clear understanding of the course. Hernández et al. [4] developed learning materials for manufacturing engineering disciplines and applied an interactive learning method to the plastic injection mold course, thereby providing numerous teaching materials for laboratory practices and multimedia. Although this multimedia teaching method can use animation demonstration to illustrate the mold design process, such method cannot clearly elaborate the specific mold design process.

The development of digital design and simulation technology has led to the extensive use of CAD/CAE/CAM technology in various disciplines [5-7]. Mold design and manufacture is one of the integrated technologies that generally set a variety of disciplines; thus, applying the three types of computer-aided technology to teaching is necessary to enable students to study in a systematic manner. Sun et al. [8] analyzed the existing problems in the teaching of mold design and proposed a five-step teaching method, which has a one-step relationship to CAD technology. However, this 
method ignored the CAE and CAM technology and did not completely associate the CAD/CAE/CAM integrated technology with mold teaching. Li et al. [9] introduced teaching innovation based on $\mathrm{CAD} / \mathrm{CAE} / \mathrm{CAM}$ technology from the teaching system, model, and testing aspects, although they did not provide specific examples. Xia [10] also proposed the importance of CAD/CAE/CAM technology in mold course learning but only through enhancing student's computer-aided technical ability to improve teaching quality. This study did not combine knowledge in mold design in the discussion. Although a few scholars have used computer-aided technology to the mold development process [11, 12], no specific description of the interrelated relationship between $\mathrm{CAD} / \mathrm{CAE} / \mathrm{CAM}$ technology and various disciplines has been established.

The current study presents a teaching method of applying CAD/CAE/CAM technology into the mold course and introduces the positive effects of these three technologies on student learning in this course. This method can eliminate the monotony of traditional teaching and enhance learning interest and efficiency. Moreover, the entire development process for mold design and manufacture is considered a separate project to strengthen the practical abilities of students. Thus, students can substantially acquire knowledge on mold, master the use of the related CAD/CAE/CAM software, and lay the foundation for future research.

\section{$3 \quad$ Methodology}

The traditional teaching of mold courses is done by illustrating theoretical knowledge in the classroom. However, such method is abstract and unintuitive, and students have difficulty in understanding the learning content because of the lack of practical experience. CAD technology is mainly used in geometric design and solid modeling, among others, thereby reducing tedious calculation and drawing on the part of students. Moreover, the mathematical model established by CAD technology has realistic shape and can clearly distinguish the mold punch, die, and push mechanism. Students can observe the model by rotating and zooming in any angle, thereby providing good visual effect and dimensional sense. In the teaching process, teachers use three-dimensional (3D) modeling to illustrate the mold structure, thereby enabling students to become considerably intuitive. The common software used for CAD includes ProE, Unigraphics, and SolidWorks, among others.

The numerical simulation and evaluation of mold model is called CAE technology. The use of CAE technology can predict the filling, packing, and cooling of the melt, as well as the shrinkage and warping deformation of the workpiece, marks, and other defects. This technology can modify the injection molding and mold design in a timely manner. Moreover, the common software used for CAE includes Moldflow, Ansys, and Polyflow, among others. The use of this technology will enable students to modify the injection molding and mold design errors in a timely manner.

After the design of the mold structure, the digital manufacturing simulation for mold components can be performed using CAM technology. The use of 3D model will enable users to specify the corresponding processing site and determine the appropriate parameters. Thereafter, the computer can automatically complete the NC 
(Numerical Control) machining program, and the dynamic tooling trajectory of a component can be displayed on the computer monitor. The common software used for CAM includes EdgeCam and MasterCam, among others. Evidently, CAD technology is considered the basis of CAE and CAM technologies.

Fig. 1 shows the relationship diagram between the CAD/CAE/CAM technology and the injection mold design and manufacturing processes. Fig. 1 shows that $\mathrm{CAD} / \mathrm{CAE} / \mathrm{CAM}$ technology occupies a significant position in the mold design process. Therefore, performing a seamless connection for the courses and $\mathrm{CAD} / \mathrm{CAE} / \mathrm{CAM}$ technology is necessary to achieve a good teaching. First, teachers should use computer-aided technology during the class to show the mold in 3D graphics, thereby providing intuitive learning to students. After the classroom discussion, teachers should provide an independent project, including mold design, simulation, and manufacture. This strategy will enhance the practical abilities of students and enable them to master the mechanical principles, material handling, manufacturing processes, and operation of various machine tools.

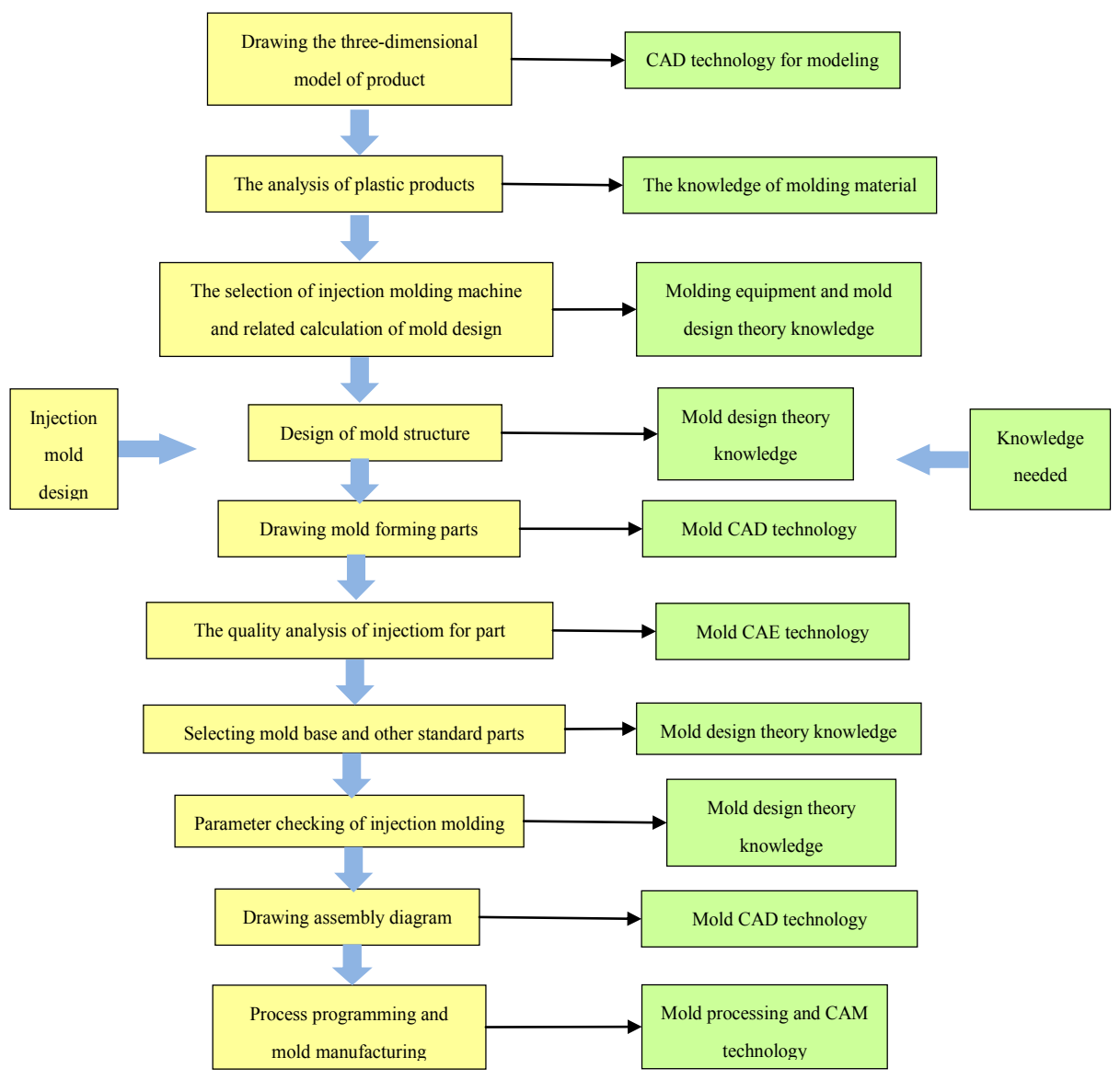

Fig. 1. CAD /CAE/CAM technology in mold design process 


\section{$4 \quad$ Teaching case and effectiveness}

\subsection{Teaching case}

This study uses a lamp cover as project carrier and adopts CAD/CAE/CAM technology to design the injection mold.

Structural design of a lamp cover mold with CAD technology: The use of the 3D modeling module in ProE software will facilitate the development of the lamp cover model through stretching, shelling, and rounding, among others (see Fig. 2). Students should apply four knowledge points in drawing: 3D solid modeling principles, methods, and general steps; surface modeling methods and general steps; sketch design function and general operation steps; and general principles, methods, and steps of feature modeling.

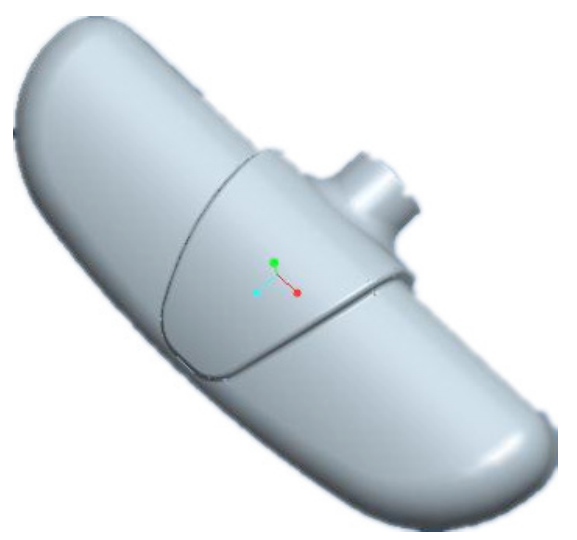

Fig. 2. Illustration of a lamp cover

The theoretical knowledge used for the structural design of the mold includes the following aspects:

1. Forming position of the plastic part and selection of the parting surface.

2. Number of cavities and position of the sprue gate.

3. Structural design of the working components of the mold.

4. Side parting and core pulling mechanism design.

5. Choice of pull rod form.

6. Design of the exhaust, heating, and cooling modes.

After determining the mold structure, ProE software was used to generate the parting surface, create pouring system, and perform mold processing, thereby eventually generating the mold components.

Fig. 3 presents the parting surface and gating system, respectively. The use of CAD technology enables the mold to be displayed clearly and observed at any angle, thereby providing students with a clear understanding of the various components of the mold. 


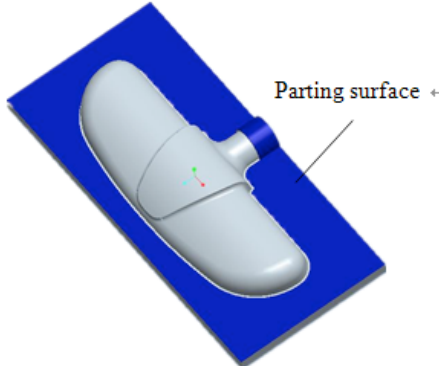

a) Parting surface of the mold

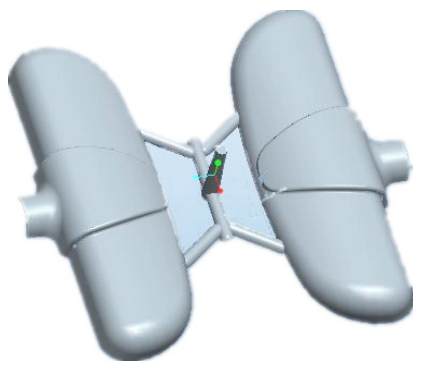

b) Gating system of the mold

Fig. 3. Parting surface and gating system of the mold

By adding the mold base and other components in the virtual assembly, the mechanism in the assembly model can be shown by generating an explosion map, thereby enabling students to perform an improved analysis of the structure and relationship of the assembly components. Animated demonstration can also introduce students to the movement during the process of opening and closing the mold, thereby encouraging them to study spontaneously and improving the study quality and effect. Fig. 4 shows a dynamic screenshot during the mold opening.

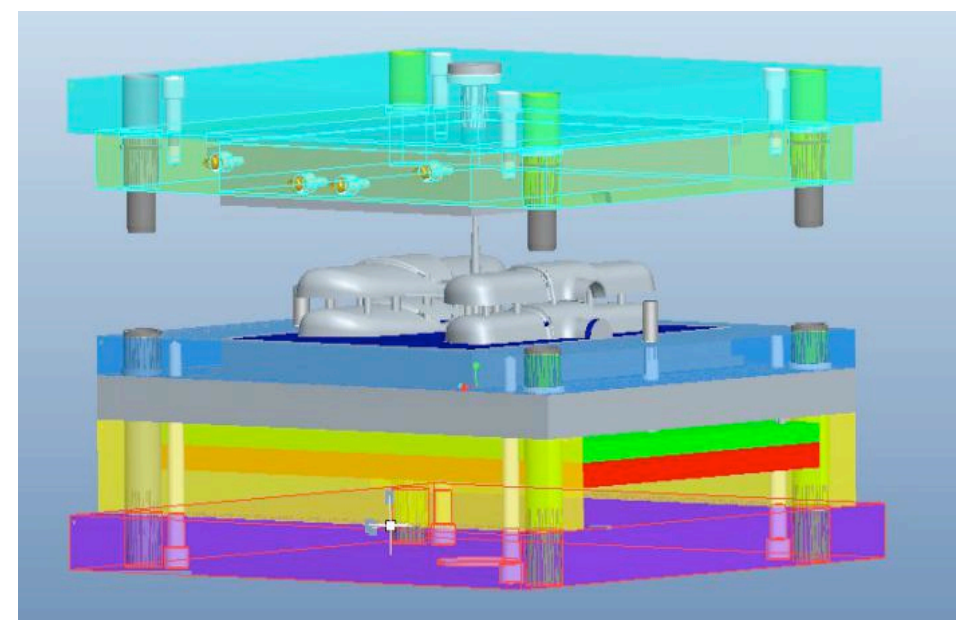

Fig. 4. Dynamic screenshot during the mold opening

Optimum design of the lamp cover mold using CAE technology: To evaluate the quality of the mold design scheme, the model is imported into Moldflow to perform flow analysis. First, the analysis mode is selected. Second, the gird is divided and repaired. Lastly, the sprue gate, main channel, and injection are set. ABS is selected as the injection material. The defects of mold design can be determined based on the analysis results. Moreover, the mold is optimized continually until the requirements for the product are obtained. The optimization results are as follows. 
1. Flow analysis: The total time of melt filling is $0.85 \mathrm{~s}$, and the animation shows that the two cavities are nearly filled simultaneously. No cavitation and welds were generated after filling. Accordingly, the filling effect was good.

2. Cooling analysis: Combined MF/Cool with MF/Flow can determine the dynamic process for injection. The temperature difference of the coolant at the inlet and outlet is approximately $2^{\circ} \mathrm{C}$. Accordingly, the temperature difference is small, that is, within the allowance range; thus, the position setting of the cooling loop is reasonable. The temperature of plastic product in the cooling process is controlled at approximately $50^{\circ} \mathrm{C}$

3. Warping analysis: The three major factors that cause warping are uneven cooling, uneven shrinkage, and inconsistent molecular orientation. Given all the factors, the overall deformation of the workpiece is $1.1 \mathrm{~mm}$, which appears at the edge (see Fig. 5). The maximum deformations caused by uneven cooling, uneven shrinkage, and orientation factor are $0.6138,0.8367$, and $0 \mathrm{~mm}$, respectively, the deformation caused by orientation factor can be ignored. Overall, these deformations meet general production requirements.

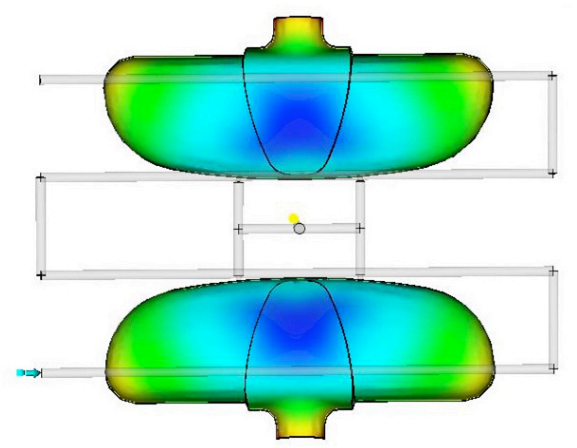

Fig. 5. Total deformation of plastic workpiece

\section{A. Machining simulation of the lamp cover mold using CAM technology}

This study uses MasterCam software to perform the machining simulation of concave and convex molds after the completion of the mold design using CAD technology. The concave mold file is imported into MasterCam and finishing machining in the order of rough machining, semi-precision machining, and precision machining. First, the blank size and required processing boundaries for the geometric figure are determined, roughing tool path is planned, and $\varphi 20$ bull mill is selected to remove most of the materials and leave a $1.5 \mathrm{~mm}$ margin. Thereafter, a $\varphi 16$ ball mill is used in the semi-precision machining, and a $0.5 \mathrm{~mm}$ finishing allowance is reserved. Lastly, the ball mill of $\varphi 12$ is selected to complete precision machining. By setting the cutting tool, processing methods, and parameters, the software will automatically generate the cutting path of the tool. Fig. 6 shows the final machining simulation result of the concave mold. The convex mold machining process is similar to that of the concave. After the simulation is completed, the NC codes can be obtained by post-processing. Accordingly, these codes can be applied to actual processing after sample adjustment. 
The entire process of mold design and manufacture is completed using $\mathrm{CAD} / \mathrm{CAE} / \mathrm{CAM}$ technology. In this process, students can exercise their ability to use various types of software, thereby enabling them to acquire a profound understanding of the mold design process

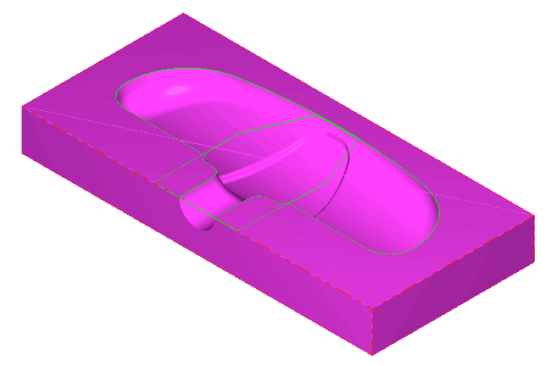

Fig. 6. Machining simulation result of concave mold

\subsection{Effectiveness}

To verify the feasibility and validity of the teaching method proposed in this study, the proposed and traditional teaching methods are implemented in classes A and B, respectively, for mold course study. The learning effect on students is investigated after the completion of the course study. Fig. 7 shows the results.

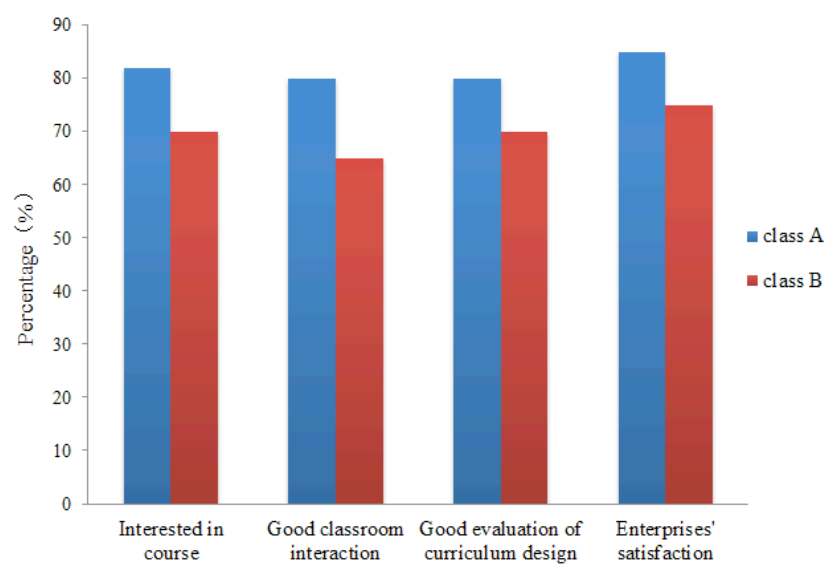

Fig. 7. Result of the teaching survey

Fig. 7 shows that the teaching effect of class $\mathrm{A}$ is better than that of class $\mathrm{B}$. In class A, students are more interested in mold courses, the classroom learning atmosphere is more active, and the curriculum design evaluation is better than those of class B. Moreover, after graduation, enterprises are considerably satisfied with the task performance of students in class A. Therefore, the proposed teaching method is proven to be feasible and has a better teaching effect than the traditional method. 


\section{Conclusions}

This study combined CAD/CAE/CAM technology with the teaching of mold courses, as well as introduced the positive role of these technologies on the teaching of mold courses. By taking the injection mold of lamp cover as an independent project, this study performed the entire process of mold design, optimization, and machining simulation. To assess the teaching effect, students and enterprises were surveyed through questionnaire. The following conclusions were drawn.

1. On the one hand, applying computer-aided technology to mold teaching enables teachers who use 3D modeling to clearly illustrate the mold structure. On the other hand, students can learn intuitively and easily, as well as enhance their learning interest and learning efficiency.

2. The use of $\mathrm{CAD} / \mathrm{CAE} / \mathrm{CAM}$ technology in the curriculum design enhances student proficiency for various modeling simulation software and enables them to use such technology to lay a strong foundation for future research.

3. The proposed teaching method meets the urgent needs of enterprises for personnel with competitive knowledge on CAD/CAE/CAM technology.

\section{Acknowledgment}

This work was supported by Postgraduate Education Innovation Program of Shandong Province (Grant No. SDYY15087), First-class Discipline Construction Project of Shandong Province, and Excellent Teaching Team Construction Plan of Shandong University of Science and Technology (Grant No. JXTD20160505).

\section{$7 \quad$ References}

[1] Y. Murata, T. Tsutsumi, D. Nakazato, R. Shigematsu, T. Kamakura and H. Noguchi, Plastic micro molding technology using ultra high speed injection machine applying dropping force of weight and micro mold prepared by focused ion beam, Seimitsu Kogaku Kaishi/Journal of the Japan Society for Precision Engineering, 2008, vol. 74(1), pp. 67-71.

[2] K. Rosentrater, J. Visser, Simulation as a means to infuse manufacturing education with statistics and DOE - A case study using injection molding, ASEE Annual Conference and Exposition, 2007.

[3] E. Tempelman, Educating industrial design engineers in injection moulding and mould construction, Proceedings of the 8th International Symposium on Tools and Methods of Competitive Engineering, 2010, vol. 1, pp. 667-676.

[4] P. Hernández, S. Taboada, L. Suáreza, M D. Marreroa, F. Ortegaa and A. Beníteza., Interactive learning tool in product development for injection moulding, Procedia Engineering, 2015, vol.132, pp. 197-204. https://doi.org/10.1016/j.proeng.2015.12.470

[5] R. V. Wilder, CAD/CAE/CAM in moldmaking: A precision tool for profitabili, Modern Plastics, 1990, vol. 67(4), pp. 56. 
[6] N, Prabhu, Dev Anand and V. Sundar, Integrated CAD/CAE/CAM system for Scorbot-ER $\mathrm{Vu}$ plus industrial robot manipulator, Applied Mechanics and Materials, 2013, vol. 389, pp. 747-753. https://doi.org/10.4028/www.scientific.net/AMM.389.747

[7] C. P. Zucuni, L. F. Guilardi, S. Fraga, L.G. May, G. K. R. Pereira and L. F. Valandro, $\mathrm{CAD} / \mathrm{CAM}$ machining Vs pre-sintering in-lab fabrication techniques of Y-TZP ceramic specimens: Effects on their mechanical fatigue behavior, Journal of the Mechanical Behavior of Biomedical Materials, 2017, vol.71, pp. 201-208. https://doi.org/10.1016/j.jmbbm. 2017.03.013

[8] X. Sun, L. J. Xu, The exploration of innovation of mould lesson in vocational college, Applied Mechanics and Materials, 2011, vol. 121-126, pp. 2318-2322.

[9] R. X. Li, S. H. Jiao, Teaching technique innovation on CAD/CAM/CAE of mold course, IERI Procedia, 2012, vol.2, pp. 137-141. https://doi.org/10.1016/j.ieri.2012.06.064

[10] B. B. Xia, Strengthening the application ability of CAD/CAE/CAM technology for mould specialty students, Digital Manufacturing Industry, 2009, vol. 1(1-2), pp. 32-34.

[11] A. F. Padalin, CAD/CAM systems and their integration in mold design, Plastics Engineering, 1996, vol. 52(10), pp. 27-28.

[12] C. Mercado, M, Jorge, M. A. Rubio-Paramio, Vizan-Idoipe and C. Martin- Donate, A new procedure for the automated design of ejection systems in injection molds, Robotics and Computer-Integrated Manufacturing, 2017, vol.46, pp. 68-85. https://doi.org/10.1016/ j.rcim.2016.12.006

\section{Authors}

Xeuyi Li (corresponding author) is an associate professor in College of Mechanical and Electronic Engineering, Shandong University of Science and Technology, Qingdao, 266590, China. He is a member of China Computer Federation (CCF) (lixueyi07@tsinghua.org.cn).

Shuhui Ding is an associate professor in College of Mechanical and Electronic Engineering, Shandong University of Science and Technology, Qingdao, 266590, China (shdingen@163.com).

Junying Wei is a lecturer in College of Mechanical and Electronic Engineering, Shandong University of Science and Technology, Qingdao, 266590, China (jdwjy0726@163.com).

Quanwei Wang is a professor in College of Mechanical and Electronic Engineering, Shandong University of Science and Technology, Qingdao, 266590, China. He is the executive director of the research institute of exchangeability and measurement technology in Chinese universities (wqw79279@163.com).

Article submitted 29 May 2017. Published as resubmitted by the authors 04 July 2017. 